Conclusions: Comorbidities typically associated with AS affect TNFi drug survival, but in different directions. Possible explanations include a differential effect of TNFi on these morbidities themselves, or other inherent differences in the AS inflammatory phenotype. The association with psoriasis decreased after adjustment, suggesting the influence of other factors. The role of inflammatory comorbidities in determining response and persistence of TNFi should be further examined.

Disclosure of Interest: U. Lindström: None declared, T. Olofsson: None declared, S. Wedrén: None declared, I. Qirjazo: None declared, J. Askling Grant/ research support from: JA has received grants from Abbvie, BMS, Merck, Pfizer, Roche, Samsung, UCB, mainly for safety monitoring via the Swedish ARTIS system

DOI: 10.1136/annrheumdis-2018-eular.1449

\section{OP0024 WHAT HAPPENS TO PATIENTS WITH ANKYLOSING SPONDYLITISWHO START A FIRST BIOLOGIC? A SWEDISH STUDY OF TREATMENT TRAJECTORIES IN CLINICAL PRACTICE}

U. Lindström ${ }^{1}$, T. Olofsson ${ }^{2}$, S. Wedrén ${ }^{1}$, I. Qirjazo ${ }^{3}$, J. Askling ${ }^{1}$, on behalf of ARTIS. ${ }^{1}$ Rheumatology Unit and Clinical Epidemiology Unit, Department of Medicine, Karolinska Institutet, Stockholm; ${ }^{2}$ Department of Clinical Sciences, Lund Univeristy, Lund; ${ }^{3}$ Rheumatology Department, Linköping University Hospital, Linköping, Sweden

Background: Clinical trials have shown that $40 \%-50 \%$ of patients with ankylosing spondylitis (AS) achieve a good response ( $>40 \%$ improvement) to treatment with tumour necrosis factor inhibitors (TNFi). By contrast, observational studies indicate that less than two out of three patients continue their first biological disease modifying anti-rheumatic drug (bDMARD) up to two years. During the past six years, five TNFi and one IL-17-inhibitor have been marketed for AS in Sweden. Yet, an assessment of long-term treatment trajectories in AS is lacking. In particular, there is a need for a better understanding of the proportion of patients who fail their first bDMARD, when this happens, and which drugs become their ensuing treatments.

Objectives: To describe contemporary five-year treatment trajectories for patients initiating a first ever bDMARD in AS, and to explore whether the dose of bDMARD is gradually tapered in those patients who remain stable on their bDMARD treatment.

Methods: Swedish patients with AS starting a first ever bDMARD in 2010-2015 were identified in the Swedish Rheumatology Quality Register (SRQ). At the end of each full year (1-5 years) after treatment start, the treatment status of each patient was determined. Censoring occurred at the first of: death, emigration, 31 December 2015 or loss to follow-up. In addition, data on collected prescriptions for the subcutaneous bDMARDs were retrieved form the National Prescribed Drug Register. For patients remaining on their first subcutaneous bDMARD, according to $S R Q$, the proportion of patients collecting $\geq 75 \%$ of the yearly 'defined daily doses' (DDD) at a pharmacy during each full year was determined. Results: 1698 patients with AS starting a first bDMARD in the study-period were identified, all of which were TNFi. After the end of the first year, $74 \%$ remained on their first bDMARD and after five years $38 \%$ (figure 1). Of the $72 \%$ of patients who remained on any bDMARD after five years, $85 \%$ were on their first or second bDMARD. After five years $24 \%$ were not on any DMARD and around five percent of the patients discontinuing bDMARD treatment did so due to low disease activity or remission. Among those remaining on their first subcutaneous bDMARD the proportion collecting $\geq 75 \%$ of the yearly DDD gradually decreased from $88 \%$ to $56 \%$ over the 5 years of follow-up (black line in figure 1 ).

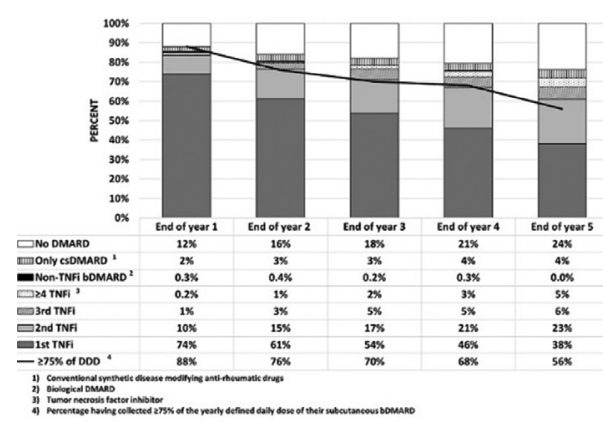

Abstract OP0024 - Figure 1 Proportion of patients with ankylosing spondylitis on each treatment after $1-5$ years of follow-up from initiating their first bDMARD
Conclusions: While a minority of patients with AS remain on their first-line bDMARD after 5 years of treatment, most are still on any bDMARD. Further, despite a low rate of discontinuation due to remission, one fourth of patients no longer use any bDMARDs treatment after 5 years. Patients remaining stable on treatment gradually but substantially decrease their use over time.

Disclosure of Interest: U. Lindström: None declared, T. Olofsson: None declared, S. Wedrén: None declared, I. Qirjazo: None declared, J. Askling Grant research support from: JA has received grants from Abbvie, BMS, Merck, Pfizer, Roche, Samsung, UCB, mainly for safety monitoring via the Swedish ARTIS system

DOI: 10.1136/annrheumdis-2018-eular.1450

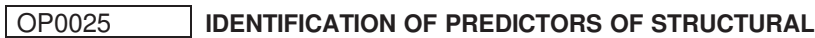 DAMAGE PROGRESSION IN THE SACROILIAC JOINTS IN PATIENTS WITH EARLY AXIAL SPONDYLOARTHRITIS ON A LONG-TERM ANTI-TNF TREATMENT}

V. Rios Rodriguez ${ }^{1 *}$, K.-G. Hermann ${ }^{2}$, H. Haibel ${ }^{1}$, C. Althoff ${ }^{2}$, O. Behmer ${ }^{3}$, J. Sieper ${ }^{1}$, D. Poddubnyy ${ }^{1,4},{ }^{1}$ Rheumatology; ${ }^{2}$ Radiology, Charité Universitätsmedizin; ${ }^{3}$ Pfizer Pharma; ${ }^{4}$ German Rheumatism Research Centre, Berlin, Germany

Background: Several observational studies showed a low, but still detectable progression of structural damage in the sacroiliac joints (SIJ) in patients with axia spondyloarthritis (axSpA) over 2 to 5 years. Few predictors of progressions, such as elevated C-reactive protein (CRP) and active inflammation on magnetic resonance imaging (MRI), have been identified, mostly in patients not treated with TNF inhibitors. To date, it is not clear whether these predictors also work in patients treated with anti-TNF agents and whether anti-TNF therapy is able to retard such a progression.

Objectives: To evaluate the radiographic progression in the sacroiliac joints (SIJ) and to identify predictors of such a progression during long-term (up to six years) treatment with tumour necrosis factor (TNF) blocker etanercept in patients with early axSpA.

Methods: In the ESTHER trial ${ }^{1}$ a total of 76 patients with early (up to 5 years symptom duration) and active axSpA were randomised to be treated with either etanercept or sulfasalazine for one year. Between year 1 and year 6 , all patients who continued in the study were treated with etanercept. X-rays of SIJ were collected at baseline and every 2 years thereafter. Two trained readers, who were blinded for all clinical data, scored independently the SIJ x-rays in a concealed and randomly selected order, according to the grading system of the modified New York (mNY) criteria (grade 0 to 4). Patients with bilateral sacroiliitis of grade $\geq 2$ or unilateral of grade $\geq 3$ were classified as radiographic axSpA ( $r$ $\operatorname{axSpA})$, and as non-radiographic axSpA (nr-axSpA) otherwise. The sacroiliitis sum score (0-8) was calculated as a sum of means of both readers for the left and right SIJ. Active and chronic inflammatory changes on MRI of SIJ were assessed at baseline, year 2 and year 4 according to the Berlin MRI scoring system. A longitudinal mixed model analysis was performed to identify predictors of the radiographic sacroiliitis progression.

Abstract OP0025 - Table 1. Longitudinal mixed model analysis of the association between structural damage in the sacroiliac joints (sacroiliitis sum score) and disease-related parameters in patients with early axSpA treated with etanercept for up to 6 years.

\begin{tabular}{lccc}
\hline Disease-related parameters & $\begin{array}{c}\text { Univariable } \\
\text { analysis } \\
B(95 \% \mathrm{Cl})\end{array}$ & $\begin{array}{c}\text { Model 1 } \\
\mathbf{B}(95 \% \mathrm{Cl})\end{array}$ & $\begin{array}{c}\text { Model 2 } \\
\mathbf{B}(95 \% \mathrm{Cl})\end{array}$ \\
\hline Elevated CRP (>5mg/l) & $\mathbf{0 . 4 4 ( 0 . 1 3 - 0 . 7 5 )}$ & - & $\mathbf{0 . 4 5 ( 0 . 1 1 - 0 . 7 8 )}$ \\
\hline SIJ osteitis score on MRI (0-24) & $\mathbf{0 . 0 5 ( 0 . 0 1 - 0 . 0 8 )}$ & $\mathbf{0 . 0 4 ( 0 . 0 1 - 0 . 0 8 )}$ & - \\
\hline Age, years & $0.00(-0.02-0.01)$ & $-0.00(-0.02-0.01)$ & $-0.00(-0.02-0.01)$ \\
\hline Male sex & $-0.03(-0.35-0.27)$ & $-0.18(-0.53-0.16)$ & $0.00(-0.33-0.33)$ \\
\hline HLA-B27 positivity & $-0.07(-0.47-0.32)$ & $-0.08(-0.55-0.38)$ & $-0.08(-0.54-0.36)$ \\
\hline Treatment duration with ETN, years & $-0.04(-0.13-0.03)$ & $-0.03(-0.15-0.09)$ & $-0.01(-0.12-0.09)$ \\
\hline Symptoms duration, years & $-0.01(-0.07-0.05)$ & $0.01(-0.07-0.11)$ & $0.01(-0.07-0.10)$ \\
\hline axSpA, axial spondyloarthritis; CRP, C-reactive protein; Cl, confidence interval; ETN, etanercept; MRI,
\end{tabular}

Results: Totally, 55 patients with axSpA contributing with 159 SIJ radiographs were included in the analysis. At baseline, 19 patients were classified as r-axSpA and 36 as $n r-a x S p A$ based on the independent SIJ reading. Radiographic progression from nr- to r-axSpA was observed in 5 (18\%) patients between baseline and year 2. Progression decelerated to $4.1 \%$ between year 2 and 4 , and no further progression was observed up to year 6 . The mean $\pm S D$ change of sacroiliitis sum score was $0.13 \pm 0.73,-0.26 \pm 0.76$ and $-0.09 \pm 0.67$, in the time intervals baselineyear 2 , year 2 year 4 , and year 4 year 6 , respectively. In the longitudinal mixed model analysis, elevated CRP (model 2) and osteitis on MRI (model 1) were independently and significantly associated with a higher sacroiliitis sum score (table 1). 